\title{
Taurine and Osmoregulation. IV. Cerebral Taurine Transport Is Increased in Rats with Hypernatremic Dehydration ${ }^{1}$
}

\author{
HOWARD TRACHTMAN, STEPHEN FUTTERWEIT, AND RICHARD DEL PIZZO \\ Department of Pediatrics, Schneider Children's Hospital, Long Island Jewish Medical Center, Long Island \\ Campus for Albert Einstein College of Medicine, New Hyde Park, New York 11042
}

\begin{abstract}
Taurine is an organic osmolyte in brain cells. We studied whether cerebral taurine transport is enhanced as part of the cell volume regulatory adaptation to hypernatremia. Hypernatremic dehydration was induced for 48 h. Synaptosomes, metabolically active nerve terminal vesicles, were isolated by homogenization of brain and purification on a discontinuous Ficoll gradient. Taurine transport was evaluated in vitro using a rapid filtration assay. After $48 \mathrm{~h}$ of hypernatremia, there was a $22.4 \%$ increment in $\mathrm{Na}^{+}$-specific taurine transport from $2.99 \pm 0.16$ to $3.66 \pm$ $0.13 \mu \mathrm{mol} / \mathrm{mg}$ protein $/ 30 \mathrm{~min}(p<0.001)$. Dehydration for $48 \mathrm{~h}$ without hypertonic saline loading had no effect on taurine uptake. Glycine transport was unaltered by hypernatremia. The adaptation in taurine uptake resulted from an enhanced $V_{\max }$ of the high affinity-low capacity transport system [265 \pm 17 , control versus $337 \pm 19 \mathrm{nmol} / \mathrm{min} /$ mg protein, experimental $(p<0.03)]$ without a change in the $\mathrm{Km}(\approx 60 \mu \mathrm{M})$. Under both control and hypernatremic conditions, $\mathrm{Na}^{+}$and $\mathrm{Cl}^{-}$were required for maximal total $\mathrm{Na}^{+}$-mediated taurine uptake. Oubain $(1 \mathrm{mM})$ decreased taurine uptake by $25 \%$, whereas addition of $\beta$-alanine or hypotaurine $(500 \mu \mathrm{M})$ to the external media reduced taurine transport by $45-65 \%$ in both control and experimental conditions $(p<0.01)$. Synaptosomal taurine uptake in hypernatremic rats was inhibited by $15-20 \%(p<0.01)$ after addition of 4-acetamido-4'-isothiocyanostilbene-2,2' disulfonic acid $(0.1 \mathrm{mM})$ or $4,4^{\prime}$-diisothiocyanostilbene$2,2^{\prime}$-disulfonic acid $(0.1 \mathrm{mM})$ to the external medium. We conclude that hypernatremic dehydration of moderate severity and duration results in stimulation of brain taurine uptake, mediated by increased activity of the $\beta$-amino acid carrier. An intact anionic binding site is required for maximal taurine uptake during hypernatremia. (Pediatr Res 32: 118-124, 1992)
\end{abstract}

\section{Abbreviations}

DIDS, 4,4' -diisothiocyanatostilbene-2,2' -disulfonic acid MOPS, 3-[N-morpholino]propane sulfonic acid

SITS, 4-acetamido-4' ${ }^{\prime}$-isothiocyanatostilbene-2,2'-disulfonic acid

Received February 18, 1991; accepted March 16, 1992

Correspondence: Howard Trachtman, M.D., Schneider Children's Hospital, Division of Pediatric Nephrology, 271-16 76th Avenue, New Hyde Park, NY 11042 .

Supported by grants from the American Heart Association, New York affiliate (Grant No. 88-023G) and the Long Island Jewish Medical Center Research Award Program.

${ }^{1}$ Presented in part at the meeting of the Society for Pediatric Research, Washington, DC, May 1989.
Regulation of cerebral cell volume in the face of osmolal stress is an important biological function in all species (1). In terrestrial mammals, the brain is encased in a rigid, bony vault. Therefore, this organ poorly tolerates sudden changes in cell size induced by changes in serum osmolality (2). Cerebral cells have developed the capacity to modulate the intracellular content of osmoprotective molecules in response to hypo- and hyperosmolal states and to minimize fluctuations in cell size (3). The important classes of compatible, organic osmolytes include inorganic ions, amino acids, polyhydric sugar alcohols, and methylamines (4).

Taurine (2-aminoethane sulfonic acid) is a constituent of the amino acid pool of nonperturbing osmoprotective molecules in invertebrate and vertebrate species $(5,6)$. It has been thought that the primary means of regulating the cytosolic pool of osmolytes during osmolal stress is release or sequestration of these molecules in subcellular organelles $(2,7)$. However, exogenous taurine supplements the cerebral cell content of osmolytes and confers protection against brain shrinkage in rats with hypernatremic dehydration (8). This suggests that altered transmembrane flux of osmoprotective molecules is part of the coordinated cerebral response to osmolal stress. Therefore, we conducted the following investigations to test the hypothesis that brain taurine uptake is increased during hypernatremic dehydration. The methodologic approach involved the use of synaptosomes, which are metabolically active nerve terminal vesicles formed by mechanical shearing forces during homogenization of the brain $(9$, 10). They can be used for in vitro assessment of changes in intrinsic cerebral membrane transport function.

\section{MATERIALS AND METHODS}

Animals. Male Sprague-Dawley rats (Taconic Farms, Germantown, NY) weighing 200-350 g were used in these experiments. They were kept in an animal facility that was maintained at $25^{\circ} \mathrm{C}$ with a 12-h light/dark cycle. They were fed rodent chow containing $22.8 \%$ protein (Ralston Purina, St. Louis, MO) and were provided water to drink ad libitum before the onset of the experiments.

All experimental protocols were approved by the Animal Utilization Review Committee of Long Island Jewish Medical Center.

Hypernatremic dehydration regimen. Hypernatremic dehydration was induced for $48 \mathrm{~h}$ according to previously described methods (11). After weighing the rats and obtaining a pretreatment serum sample for chemical analysis, animals were totally deprived of water for $24 \mathrm{~h}$. The rats were weighed the next day and received intraperitoneal injections of $1 \mathrm{M} \mathrm{NaCl}$ in a dose designed to raise the serum $\mathrm{Na}^{+}$concentration to $180 \mathrm{mmol} / \mathrm{L}$ over the next $24 \mathrm{~h}$. The dose was calculated according to the 
following formula:

Volume of $1 \mathrm{M} \mathrm{NaCl}(\mathrm{mL})=0.6 \times$ body weight $\times(180-140)$

Rats were provided food but not water during the period of hypernatremia. Animals with dehydration due to water deprivation alone were denied access to drinking water for a total of $48 \mathrm{~h}$, but did not receive hypertonic saline injections. Control rats, which had free access to water and were given sham injections, were studied in parallel with experimental animals. In each synaptosome preparation procedure, two to four animals evenly divided between the control and hypernatremic conditions were studied. At the completion of each regimen, animals were killed by decapitation. A free-flowing, nonhemolyzed blood sample was obtained from the stump for determination of serum $\mathrm{Na}^{+}$ concentration. The brains were excised and placed in an ice-cold isolation medium containing (in $\mathrm{mM}$ ) sucrose 320 , Tris- $\mathrm{HCl} 10$, and K-EDTA 1, pH 7.4, for preparation of synaptosomes. All subsequent procedures were performed at $0-4^{\circ} \mathrm{C}$.

Isolation of synaptosomes. Synaptosomes were isolated according to the procedure described by Fraser et al. (12). Brains were minced with a scalpel, washed three times to remove blood and extraneous tissue fragments, brought up to $15 \mathrm{~mL}$ with isolation medium, and then homogenized with 15 strokes of a glass Dounce homogenizer (Wheaton, Millville, NJ). Cellular debris was removed by centrifuging the homogenates at $1300 \times g$ for $3 \mathrm{~min}$. The supernatant was respun at $18000 \times g$ for $10 \mathrm{~min}$ to obtain the crude synaptosome pellet. The pellet was resuspended in $15 \mathrm{~mL}$ of isolation medium by homogenization with three strokes. This suspension, obtained from one to two animals, was layered onto a discontinuous Ficoll gradient composed of 11 and $7.5 \%$ layers, each $12.5 \mathrm{~mL}$ in volume. The Ficoll was dialyzed for $5 \mathrm{~h}$ before being used to remove low molecular weight fragments. The gradients were spun at $100000 \times g$ for $70 \mathrm{~min}$, and the synaptosomes were isolated from the interface between the 7.5 and $11 \%$ Ficoll layers. Synaptosomes were aspirated by gentle suction with a plastic pipette, brought up to $15 \mathrm{~mL}$ with isolation medium, and then spun at $17000 \times \mathrm{g}$ for $10 \mathrm{~min}$. Purified synaptosomes were then resuspended in a total volume of isolation medium designed to yield a protein concentration of 4-6 $\mathrm{mg} / \mathrm{mL}$ and then divided into $0.5-1.0 \mathrm{~mL}$ aliquots. The synaptosomes were stored at $-70^{\circ} \mathrm{C}$ and used within 3 mo of preparation.

Ultrastructural examination. Several drops of the freshly prepared synaptosomes that had been resuspended in isolation medium were placed for $2 \mathrm{~h}$ in modified Karnovsky's fixative, containing $2.5 \%$ glutaraldehyde and $2 \%$ paraformaldehyde in a $0.1 \mathrm{M}$ sodium cacodylate buffer. The specimen was spun at 4000 $\mathrm{rpm}$ for $10 \mathrm{~min}$. The supernatant was discarded and the pellet was gradually heated to $60^{\circ} \mathrm{C}$. A $2 \%$ solution of liquid agar at $60^{\circ} \mathrm{C}$ was added and allowed to infiltrate the pellet for $10 \mathrm{~min}$. After cooling,the pellet was cut into several pieces measuring 1$2 \mathrm{~mm}$ on a side and placed in a $0.1 \mathrm{M}$ sodium cacodylate buffer overnight. The specimen was postfixed in $1 \%$ osmium tetroxide for $1 \mathrm{~h}$, dehydrated in an ethanol series, substituted with propylene oxide, and then infiltrated with plastic embedding medium (Polybed 812; Polysciences, Inc., Warrington, PA) and polymerized overnight at $65^{\circ} \mathrm{C}$ in Beem capsules (Electron Microscopy Sciences, Fort Washington, PA). Sections of the specimen were cut, stained with uranyl acetate and lead citrate, and examined and photographed with a JEM 100B electron microscope (JEOL, Japan).

Measurements of internal volume. The internal volume of the synaptosomes was determined by incubating an aliquot of the resuspended vesicles for $10 \mathrm{~min}$ in a preequilibration medium containing (in $\mathrm{mM}$ ) KCl $150, \mathrm{MgCl}_{2}$, and MOPS 5, pH 7.4, at $37^{\circ} \mathrm{C}$, to which was added ${ }^{3} \mathrm{H}-\mathrm{H}_{2} \mathrm{O}$ and ${ }^{14} \mathrm{C}$-inulin. The synaptosomes were then spun at $20000 \times g$ for $10 \mathrm{~min}$ through mineral oil to facilitate separation of synaptosomes from the medium. The difference between the ${ }^{3} \mathrm{H}-\mathrm{H}_{2} \mathrm{O}$ and ${ }^{14} \mathrm{C}$-inulin counts in the medium after equilibration and centrifugation was used to calculate the internal volume of the synaptosomes, expressed as $\mu \mathrm{L} /$ mg protein.

Assays of synaptosome integrity and purity. The integrity of the synaptosomes was determined by assaying the lactate dehydrogenase enzyme activity in the medium before and after adding Triton $\mathrm{X}-100,0.5 \% \mathrm{vol}$, to the sample. The rate of NADH formation was measured by monitoring the conversion of lactate to pyruvate at $340 \mathrm{~nm}$. The purity of the synaptosome preparation was evaluated by measuring rotenone-insensitive NADH and NADPH cytochrome $c$ reductase activities in $3 \mathrm{~mL}$ of a reaction mixture containing (in $\mathrm{mM}$ ) $\mathrm{KCN} \mathrm{0.3,} \mathrm{NAD}(\mathrm{P}) \mathrm{H} 0.1$, cytochrome $c 0.1$, rotenone 1.5 , and $\mathrm{K}_{2} \mathrm{HPO}_{4} 50$, pH 7.4. Synaptosomal protein, $25 \mu \mathrm{L}$, was added to start the reaction, which was monitored at $550 \mathrm{~nm}$ in a temperature-controlled spectrophotometer (Perkin Elmer, Norwalk, CT) at $25^{\circ} \mathrm{C}$. The extinction coefficient of cytochrome $c$ was taken to be 21.1 (13).

Transport assay. Taurine uptake was measured using $1 \mathrm{~mL}$ of synaptosomal protein containing $4-6 \mathrm{mg} / \mathrm{mL}$. Thawed samples were incubated in $5 \mathrm{~mL}$ of the preequilibration medium for 10 $\min$ at $37^{\circ} \mathrm{C}$. The suspension was spun at $20000 \times g$ for $5 \mathrm{~min}$ and the pellet was resuspended in $250-300 \mu \mathrm{L}$ of the preequilibration medium. The pellet was gently aspirated through a 25 gauge needle 3 to 5 times to ensure a homogeneous synaptosome suspension. Synaptosomes were maintained at $0-4^{\circ} \mathrm{C}$ until aliquots of the suspension were added to individual assay tubes. External media contained (in $\mathrm{mM}$ ) $\mathrm{NaCl}$ or $\mathrm{KCl} 140, \mathrm{MgCl}_{2}$ 5, EGTA 0.2 , MOPS 5, and taurine 0.1 . Ten $\mu \mathrm{Ci}$ of ${ }^{3} \mathrm{H}$-taurine were added to $4 \mathrm{~mL}$ of external medium. Glycine uptake was assayed using $\mathrm{Na}^{+}$and $\mathrm{K}^{+}$external media containing $0.1 \mathrm{mM}$ glycine and $10 \mu \mathrm{Ci}$ of ${ }^{3} \mathrm{H}$-glycine. In the ionic requirement studies, external medium contained an equimolar amount of choline or gluconate instead of $\mathrm{Na}^{+}$or $\mathrm{Cl}^{-}$, respectively. In the inhibitor studies, oubain $(1 \mathrm{mM}), \beta$-alanine $(500 \mu \mathrm{M})$, hypotaurine $(500 \mu \mathrm{M}), \beta$-amino-isobutyric acid $(500 \mu \mathrm{M})$, SITS $(0.1$ and $5 \mathrm{mM})$, or DIDS $(0.1$ and $5 \mathrm{mM})$ were added individually to $\mathrm{Na}^{+}$-containing external media. The studies involving ionic substitutions, competing amino acids, and the addition of oubain, SITS, or DIDS were performed simultaneously and in parallel with samples containing standard $\mathrm{Na}^{+}$-external medium.

Transport studies were started by adding 7.5-10 $\mu \mathrm{L}$ of the synaptosome suspension to $95 \mu \mathrm{L}$ of external medium. The assay tubes were incubated for $5,10,20,30,60,90$, and $120 \mathrm{~min}$ at $37^{\circ} \mathrm{C}$. These time points were selected based upon the work of Kontro and Oja $(14,15)$. Each time point was tested in triplicate. Uptake was halted by adding $2 \mathrm{~mL}$ of ice-cold stop solution, 150 $\mathrm{mM} \mathrm{KCl}$, and the mixture was vacuum-filtered through presoaked $0.45-\mu \mathrm{m}$ pore size cellulose acetate membranes (Millipore, Bedford, MA). The zero points were determined by adding the synaptosomal protein suspension to assay tubes that already contained ice-cold stop solution and then filtering the suspension.

Analysis of the kinetics of synaptosomal taurine uptake was performed after 15 min of incubation with external media containing $1,2.5,5,10,25,50,100,250,500,750$, and $1000 \mu \mathrm{M}$ taurine. This time point was midway along the linear portion of the synaptosomal uptake curve that extended from 5 to $30 \mathrm{~min}$.

Analytic methods. Serum $\mathrm{Na}^{+}$concentrations were determined using an ion-selective electrode analyzer (Beckman, Fullerton, CA). Synaptosomal protein concentration was measured in each transport experiment using the Coommassie blue reagent assay (Quantimetrix, Hawthorne, CA).

Materials. ${ }^{3} \mathrm{H}$-Taurine, ${ }^{3} \mathrm{H}$-glycine, ${ }^{3} \mathrm{H}-\mathrm{H}_{2} \mathrm{O}$, and ${ }^{14} \mathrm{C}$-inulin were purchased from DuPont-New England Nuclear Corp. (Boston, MA). All other chemicals and enzyme assay kits were reagent grade and were purchased from Sigma Chemical Co. (St. Louis, MO).

Statistical methods. The uptake at each time point was determined as the average of the triplicate determinations in each experimental condition. The overall data represent the mean of $n$ experiments performed from a number of synaptosome prep- 
arations, indicated by $N$. In general, each synaptosome preparation yielded sufficient protein to conduct eight to ten experiments. The differences in taurine uptake between the various experimental conditions were compared using the paired $t$ test with the Bonferroni correction for multiple comparisons (16). The kinetic parameters of taurine transport were calculated using an Eadie-Hofstee plot (v/[S] versus $\mathrm{v})$ of the data, where $\mathrm{v}$ is the transport rate and [S] is the external media taurine concentration. Differences in the $\mathrm{V}_{\max }$ and $\mathrm{Km}$ were determined using linear regression analysis and a paired $t$ test. All differences between groups were considered statistically significant if the $p$ value was less than 0.05 .

\section{RESULTS}

In rats with $48 \mathrm{~h}$ of hypernatremia, the general activity level, including feeding and grooming, was indistinguishable from that displayed by normal animals. This protocol resulted in an elevation in the serum $\mathrm{Na}^{+}$concentration to $167 \pm 2 \mathrm{mmol} / \mathrm{L}$ and a $13.5 \pm 1.1 \%$ reduction in body $w t$. The dehydration regimen with water deprivation alone resulted in a $12.1 \pm 2.4 \%$ wt loss. The serum $\mathrm{Na}^{+}$concentration in these rats was $5 \mathrm{mmol} / \mathrm{L}$ higher than in concurrent control rats (Table 1).

Synaptosomes isolated from rats with dehydration due to water deprivation or $48 \mathrm{~h}$ of hypernatremic dehydration had an ultrastructural appearance similar to those obtained from control animals. They were bound by a bilayered lipid membrane and contained neurotransmitter vesicles and mitochondria (Figs. 1 and 2). The internal volume of all synaptosomes was in the range of $4.0-5.5 \mu \mathrm{L} / \mathrm{mg}$ protein and they retained their integrity despite storage for up to $3 \mathrm{mo}$ at $-70^{\circ} \mathrm{C}$. This was based on a consistent 8- to 10 -fold increment in medium lactate dehydrogenase concentration after incubation of the synaptosomes with Triton X$100(0.5 \% \mathrm{vol} / \mathrm{vol})$ (Table 2$)$. The contamination with free mitochondria or endoplasmic reticulum membrane was always less than $8 \%$, based upon the difference in the enzyme activities of rotenone-insensitive NADH- and NADPH-dependent cytochrome $c$ reductase (Table 2).

Taurine and glycine uptake in the presence of external $\mathrm{KCl}$ medium, which represents nonspecific binding and passive diffusion of the amino acid into synaptosomes, was $25-30 \%$ of total transport in the presence of an inwardly directed $\mathrm{Na}^{+}$gradient. $\mathrm{Na}^{+}$-specific taurine and glycine transport values were calculated as the difference in uptakes in the presence of external $\mathrm{NaCl}$ and $\mathrm{KCl}$. In the ionic requirement and inhibitor experiments, only the total $\mathrm{Na}^{+}$-mediated taurine uptake after a 30-min incubation was measured. Preliminary experiments indicated that during this time interval, $\mathrm{K}^{+}$-mediated uptake was similar in all of the external media tested. Therefore, changes in the total taurine transport reflect alterations in the specific $\mathrm{Na}^{+}$-mediated carrier activity.

Specific $\mathrm{Na}^{+}$-mediated cerebral taurine uptake was significantly higher at all time points beyond $5 \mathrm{~min}$ in rats with hypernatremic dehydration, compared to control rats (Fig. 3). Storage of synaptosomes at $-70^{\circ} \mathrm{C}$ had no effect on taurine transport. An assay of uptake in freshly prepared synaptosomes from rats with $48 \mathrm{~h}$ of hypernatremic dehydration demonstrated a $17 \%$ increase in $\mathrm{Na}^{+}$-specific taurine transport compared to synaptosomes isolated from control animals. The stability of synaptosomal taurine uptake in stored vesicles is in accord with previous work investigating cerebral ion transport in which frozen synaptosomes were used (12).

No significant enhancement of synaptosomal taurine uptake was noted in water-deprived rats that did not receive injections of $1 \mathrm{M} \mathrm{NaCl}$. After a 30-min incubation, $\mathrm{Na}^{+}$-specific taurine uptake was $3.23 \pm 0.23$ in dehydrated rats compared to $3.11 \pm$ $0.23 \mu \mathrm{mol} / \mathrm{mg}$ protein in control animals $(p>0.3 ; N=3, n=$ 16).

Replacement of external $\mathrm{NaCl}$ with equimolar amounts of choline chloride or sodium gluconate resulted in a $55-85 \%$ decrement in total taurine uptake after a 30 -min incubation period under both control and hypernatremic dehydration conditions (Table 3 ). Inhibition of Na-K ATPase activity with ouabain $(1 \mathrm{mM})$ decreased synaptosomal taurine uptake by $25 \%$. Addition of $\beta$-alanine or hypotaurine $(500 \mu \mathrm{M})$ to the external medium lowered taurine transport by $45-65 \%$ in synaptosomes isolated from control and hypernatremic rats. Addition of $\beta$ aminoisobutyric acid $(500 \mu \mathrm{M})$ reduced taurine uptake by $27 \%$ in synaptosomes isolated from hypernatremic rats, but had no inhibitory effect on taurine transport in control synaptosomes (Table 3). Addition of SITS or DIDS $(0.1$ or $5 \mathrm{mM})$ reduced taurine transport by $15-20 \%(p<0.01)$ in synaptosomes isolated from rats with hypernatremic dehydration, but had no effect on taurine uptake in control synaptosomes.

$\mathrm{Na}^{+}$-specific glycine uptake after a 30 -min incubation was similar in control and experimental animals $(9.79 \pm 0.40$ versus $9.56 \pm 0.27 \mu \mathrm{mol} / \mathrm{mg}$ protein, respectively; $p>0.2 ; N=3, n=$ 9).

The kinetic characteristics of taurine uptake in synaptosomes isolated from control rats and those with $48 \mathrm{~h}$ hypernatremic dehydration demonstrated that under both control and hypernatremic conditions, the graphs were curvilinear over the taurine concentration range tested $(1-1000 \mu \mathrm{M})$ (Fig. 4). This indicated the presence of two transport systems. Hypernatremic dehydration caused an adaptive increase of $27 \%$ in the $\mathrm{V}_{\max }$ value from $265 \pm 17$ to $337 \pm 19 \mathrm{nmol} / \mathrm{mg}$ protein $/ \mathrm{min}(p<0.03)$. There was no significant change in the affinity of this carrier system (Km for taurine, $61 \pm 10$ control versus $63 \pm 9 \mu \mathrm{M}$ experimental). The $\mathrm{V}_{\max }$ and $\mathrm{Km}$ of the low affinity-high capacity taurine uptake mechanism were not altered during $48 \mathrm{~h}$ of hypernatremia dehydration (Table 4).

\section{DISCUSSION}

Our findings indicate that hypernatremia of modest severity and duration results in an adaptive increase in cerebral taurine uptake. This alteration in transport represents an intrinsic change in membrane function that is preserved in a controlled in vitro system. The increment in taurine uptake is a response to hyperosmolality per se and not to loss of body weight. The cerebral

Table 1. General animal data*

\begin{tabular}{|c|c|c|c|c|}
\hline & \multicolumn{2}{|c|}{$48 \mathrm{~h} \mathrm{CHD} \dagger(N=11)$} & \multicolumn{2}{|c|}{$48 \mathrm{~h}$ dehydration $(N=3)$} \\
\hline & Control $(n=23)$ & Experimental $(n=26)$ & Control $(n=23)$ & Experimental $(n=26)$ \\
\hline \multicolumn{5}{|c|}{ Weight (g) } \\
\hline Final & $270 \pm 16$ & $224 \pm 16 \ddagger$ & $308 \pm 44$ & $286 \pm 62 \ddagger$ \\
\hline \multicolumn{5}{|c|}{ Serum $\mathrm{Na}^{+}(\mathrm{mmol} / \mathrm{L})$} \\
\hline Initial & $142 \pm 1$ & $143 \pm 1$ & $142 \pm 1$ & $141 \pm 1$ \\
\hline
\end{tabular}

\footnotetext{
* Results are mean $\pm \mathrm{SEM} ; N$ refers to the number of synaptosome preparations, whereas $n$ refers to the number of animals.

$\uparrow \mathrm{CHD}$, chronic hypernatremic dehydration.

$\ddagger p<0.01$ vs experimental, initial and control, final.
} 


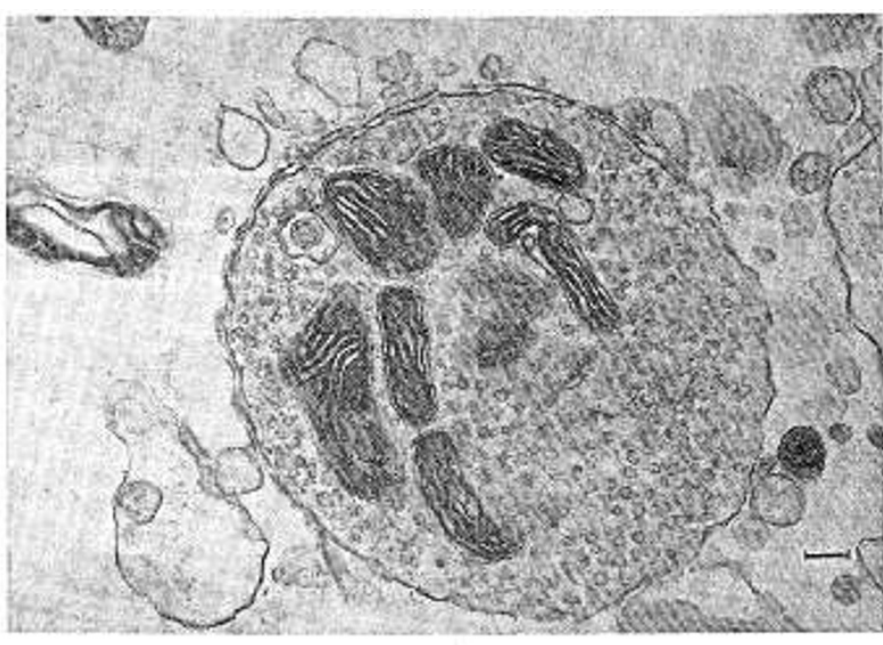

Fig. 1. Electron micrograph demonstrating an intact synaptosome isolated from control normonatremic rats, enveloped by a bilayered lipid membrane and containing mitochondria $(\times 80000)$. The bar in the lower right hand corner indicates a $10-\mathrm{nm}$ scale.

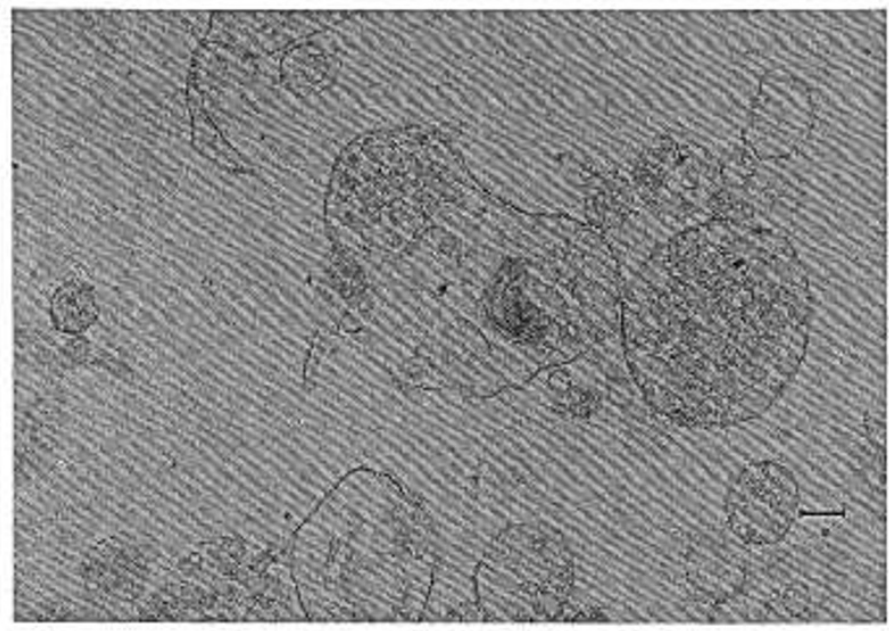

Fig. 2. Electron micrograph of intact synaptosomes isolated from experimental animals with $48 \mathrm{~h}$ of hypernatremic dehydration $(\times 80000)$. The bar in the lower right hand corner indicates a $10-\mathrm{nm}$ scale. Note the similar appearance to the synaptosomes prepared from control rats, illustrated in Figure 1.

adaptation appears to involve only osmolytes and does not reflect a generalized defect in amino acid transport. The modification in taurine transport results from modulation of the $\beta$-amino acid carrier, based upon the ionic requirements for taurine transport and the effect of anionic transport inhibitors and competing amino acids (17). The change in taurine uptake reflects upregulation of the number or rate of turnover and not the $\mathrm{Km}$ of the high-affinity taurine transporter for its substrate. A comparable change in the kinetics of taurine transport has been reported in membrane vesicles isolated from guinea pigs with hyperglycemia (18).

Synaptosomes isolated from rats with hypernatremic dehydration and controls did not display any morphologic or functional differences (Table 2). These features were virtually identical to those reported by Fraser et al. (12). Thus, passive uptake into synaptosomes of varying size or transport by contaminating organelle membranes cannot account for the differences in taurine transport between hypernatremic and control animals.

The configuration of the taurine uptake curve with a slow, gradual rise for $30 \mathrm{~min}$ followed by a plateau phase between 30 and $120 \mathrm{~min}$ is similar to the pattern observed in brain synaptosomes $(14,15)$ and in intact cells such as type II alveolar pneumocytes (19). The different time course of taurine uptake in these systems versus renal brush border membrane vesicles, in which there is a rapid overshoot followed by a delayed equilibration $(20-22)$, is probably due to inclusion of mitochondria within the synaptosomes (Figs. 1 and 2). This may enable prolonged maintenance of the transmembrane $\mathrm{Na}^{+}$gradient, which serves as the driving force for secondary active taurine transport by the $\beta$-amino acid carrier system. The inhibition of taurine transport by oubain indicates that synaptosomal $\mathrm{Na}^{+}-\mathrm{K}^{+}$ATPase activity contributes to the maintenance of the $\mathrm{Na}^{+}$gradient.

The dependence of taurine uptake on external $\mathrm{Na}^{+}$and $\mathrm{Cl}^{-}$ was similar in synaptosomes isolated from control and hypernatremic rats. Although the stoichiometric ratio between $\mathrm{Na}^{+}$, $\mathrm{Cl}^{-}$, and taurine was not investigated in these studies, previous work indicates that it is likely to be $\geq 2: 1: 1(22-24)$. The inhibitory effect of SITS and DIDS on synaptosomal taurine uptake in hypernatremic rats indicates the importance of an intact anionic binding site in mediating taurine uptake. SITS and DIDS exert a comparable effect on taurine uptake in renal brush border membrane vesicles (22) and taurine efflux from cultured astrocytes (25) and skate erythrocytes (26) during exposure to hypotonic media.

Synaptosomal taurine uptake was reduced by competing $\beta$ amino acids under both experimental conditions. The sensitivity of synaptosomal taurine transport to these agents differed from renal brush border membrane vesicles $(5,20,21)$, human placental membrane vesicles (27), isolated rat brain capillaries (28), or pulmonary macrophages and type II pneumocytes (19). The diminished inhibitory capacity of $\beta$-aminoisobutyric acid versus $\beta$-alanine and hypotaurine may occur because $\beta$-aminoisobutyric acid is sterically too large to compete with taurine for cerebral uptake (29). Differences in inhibition of cerebral taurine transport in synaptosomes isolated from control versus hypernatremic rats achieved by $\beta$-aminoisobutyric acid, SITS, and DIDS may be due to changes in the $\beta$-amino acid carrier in response to hypernatremia or hyperchloremia.

The adaptive increase in cerebral taurine uptake during hypernatremic dehydration may be a consequence, in part, of changes in the electrogenic component of taurine uptake due to an altered transmembrane potential induced by hypernatremia. However,

Table 2. Characteristics of synaptosomes from normal and experimental rat brain*

\begin{tabular}{|c|c|c|c|c|c|c|}
\hline & & & $\mathrm{NADH}$ & NADPH & \multirow{3}{*}{$\begin{array}{l}\% \text { Mitochondrial } \\
\text { contamination }\end{array}$} & \multirow{3}{*}{$\begin{array}{l}\text { Internal volume } \\
(\mu \mathrm{L} / \mathrm{mg} \text { protein })\end{array}$} \\
\hline & \multicolumn{2}{|c|}{$\mathrm{LDH}(\mathrm{U} / \mathrm{min} / \mathrm{mg}$ protein $)$} & \multirow{2}{*}{\multicolumn{2}{|c|}{$\begin{array}{c}\text { (cytochrome with } \\
\text { reductase) } \\
\text { (nmol/min/mg protein) }\end{array}$}} & & \\
\hline & (-) Triton & (+) Triton & & & & \\
\hline Control $(N=11)$ & $814 \pm 65$ & $7513 \pm 728 \dagger$ & $3.8 \pm 0.9$ & $0.4 \pm 0.1$ & $8.1 \pm 3.6$ & $4.8 \pm 0.2$ \\
\hline 48-h CHD $\$(N=11)$ & $833 \pm 162$ & $7628 \pm 863 \dagger$ & $3.0 \pm 0.3$ & $0.5 \pm 0.1$ & $6.0 \pm 1.3$ & $4.6 \pm 0.2$ \\
\hline Dehydration $(N=3)$ & $756 \pm 93$ & $6536 \pm 957 \dagger$ & $3.3 \pm 0.2$ & $0.3 \pm 0.1$ & $7.1 \pm 2.1$ & $4.4 \pm 0.3$ \\
\hline
\end{tabular}

* Results are mean $\pm \mathrm{SEM} ; N$ refers to the number of synaptosome preparations.

$\dagger p<0.001$ vs $(-)$ Triton.

$\ddagger \mathrm{CHD}$, chronic hypernatremic dehydration. 


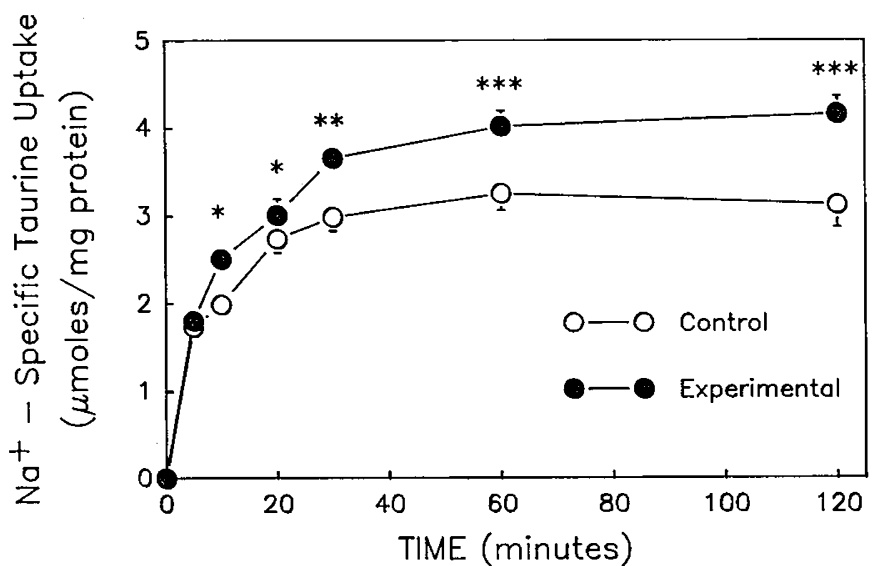

Fig. 3. Graphic illustration of $\mathrm{Na}^{+}$-specific taurine uptake in synaptosomes isolated from control $(O)$ and experimental $(\bullet)$ rats with $48 \mathrm{~h}$ of hypernatremic dehydration. The synaptosomes were incubated for the indicated times in external media containing $140 \mathrm{mM} \mathrm{NaCl}$ or $140 \mathrm{mM}$ $\mathrm{KCl}$ and $100 \mu \mathrm{M}$ taurine. Each time point was assayed in triplicate and the curves represent the mean of 16 paired experiments from seven synaptosomal preparations. ${ }^{*}, p<0.03 ;{ }^{* *}, p<0.01$; and ${ }^{* * *}, p<0.001$.

Table 3. Synaptosomal taurine uptake in control and $48-h$ chronic hypernatremic dehydration (CHD) condition: inhibitor studies*

\begin{tabular}{llll}
\hline & $n$ & Control (\%) & 48-h CHD (\%) \\
\hline $\begin{array}{l}\text { Total taurine uptake } \\
\text { Ionic substitutions }\end{array}$ & 3 & $4.25 \pm 0.07$ & $4.78 \pm 0.07 \dagger$ \\
$\quad$ Choline & 3 & $0.71 \pm 0.05(17) \ddagger$ & $0.71 \pm 0.01(15) \ddagger$ \\
$\quad$ Gluconate & 5 & $1.87 \pm 0.08(44) \ddagger$ & $1.83 \pm 0.10(38) \ddagger$ \\
Oubain $(1 \mathrm{mM})$ & 5 & $3.20 \pm 0.08(75) \ddagger$ & $3.63 \pm 0.12(76) \ddagger$ \\
Amino acid additions & & & \\
$\quad \beta$-alanine $(500 \mu \mathrm{M})$ & 3 & $2.35 \pm 0.10(55) \ddagger$ & $2.48 \pm 0.05(52) \ddagger$ \\
Hypotaurine $(500 \mu \mathrm{M})$ & 3 & $1.55 \pm 0.09(36) \ddagger$ & $1.81 \pm 0.05(38) \ddagger$ \\
$\beta$-aminoisobutyrate & 3 & $3.82 \pm 0.18(90)$ & $3.48 \pm 0.07(73) \ddagger$ \\
$\quad(500 \mu \mathrm{M})$ & & & \\
Anion transport inhibitors & & & \\
$0.1 \mathrm{mM}$ SITS & 4 & $3.99 \pm 0.14(94)$ & $3.82 \pm 0.05(80) \ddagger$ \\
$5 \mathrm{mM}$ SITS & 4 & $3.92 \pm 0.20(92)$ & $4.15 \pm 0.22(87) \ddagger$ \\
$0.1 \mathrm{mM}$ DIDS & 4 & $3.88 \pm 0.14(91)$ & $4.05 \pm 0.04(85) \ddagger$ \\
$5 \mathrm{mM}$ DIDS & 4 & $3.92 \pm 0.25(92)$ & $4.08 \pm 0.09(85) \ddagger$ \\
\hline
\end{tabular}

* Total taurine uptake ( $\mu \mathrm{mol} / \mathrm{mg}$ protein) was assayed after a 30 -min incubation period in the absence or presence of ionic substitutions, inhibitor agents, or competing amino acids. Ionic substitutions involved equimolar replacement of $\mathrm{Na}^{+}$or $\mathrm{Cl}^{-}$with choline or gluconate, respectively. Competing amino acids were added to $\mathrm{Na}^{+}$-containing external medium in a concentration of $500 \mu \mathrm{M}$. Anionic binding inhibitors and oubain were added to the $\mathrm{Na}^{+}$-containing external medium at the indicated concentration. The values in parentheses represent the $\%$ of the total taurine uptake in the presence of standard $\mathrm{Na}^{+}$-containing external media in synaptosomes isolated from the corresponding control or hypernatremic animals. CHD, chronic hypernatremic dehydration.

$\dagger p<0.02$ vs control, total 30-min taurine uptake.

$\ddagger p<0.005$ vs total 30-min taurine uptake, same experimental condition.

the bulk of the enhanced cerebral taurine transport is mediated by a change in the number or turnover rate of the $\beta$-amino acid carrier. Alterations in the kinetics of membrane taurine transport during hypernatremic dehydration may result from modifications of the lipid composition of the synaptosome membrane $(30,31)$. Alternatively, hyperosmolal states may stimulate increased synthesis of new carrier proteins.

The failure of dehydration induced by water deprivation without concomitant injections of $1 \mathrm{M} \mathrm{NaCl}$ to activate cerebral uptake of taurine is consistent with work in which salt-loading

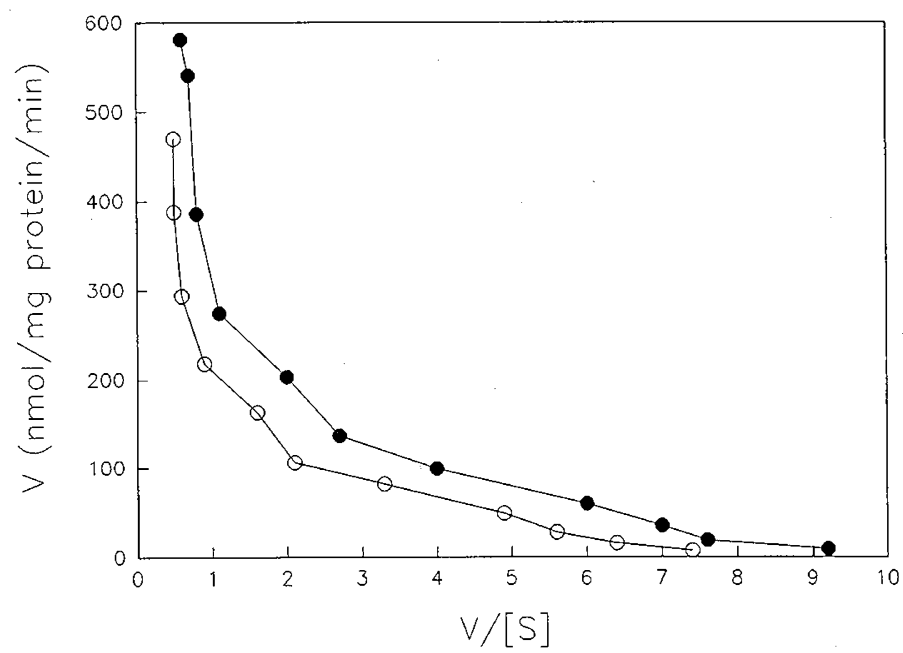

Fig. 4. Eadie-Hofstee plots of the uptake data over an external medium taurine concentration range of $1-1000 \mu \mathrm{M}$ from control rats $(\mathrm{O})$ and animals with $48 \mathrm{~h}$ of hypernatremic dehydration (-). The results represent the mean of eight paired experiments performed using five synaptosome preparations.

Table 4. Synaptosomal taurine uptake: kinetic analysis*

\begin{tabular}{llllrl}
\hline & \multicolumn{2}{c}{ High-affinity system $\dagger$} & & \multicolumn{2}{c}{ Low-affinity system $\dagger$} \\
\cline { 2 - 3 } \cline { 5 - 6 } \cline { 5 - 6 } & \multicolumn{1}{c}{$\mathrm{V}_{\max }$} & \multicolumn{1}{c}{$\mathrm{Km}$} & & \multicolumn{1}{c}{$\mathrm{V}_{\max }$} & $\mathrm{Km}$ \\
\hline Control & $265 \pm 17$ & $61 \pm 10$ & & $829 \pm 170$ & $815 \pm 312$ \\
48-h CHD & $337 \pm 19 \ddagger$ & $63 \pm 9$ & & $1012 \pm 170$ & $720 \pm 236$ \\
\hline
\end{tabular}

* Results are mean \pm SEM. The values represent the results of seven transport studies from two synaptosome preparations. CHD, chronic hypernatremic dehydration.

$\dagger \mathrm{V}_{\max }, \mathrm{nmol} / \mathrm{mg}$ protein/min; $\mathrm{Km}, \mu \mathrm{M}$.

$\$ p<0.03$ vs control.

provoked an accumulation of cerebral osmolytes, whereas water deprivation was an inadequate stimulus for this response (32). In contrast, in normal and Brattleboro rats, the renal inner medullary cell volume response is triggered by dehydration alone in the presence of arginine vasopressin $(33,34)$.

Taurine is an important osmoprotective molecule in invertebrate marine species and in aquatic and terrestrial vertebrates (1, 35-37). It has been assumed that during cerebral cell volume regulation, fluctuations in the cytosolic levels of osmolytes are mediated by release and reuptake of osmolytes into subcellular sequestration sites $(2,7)$. However, recent data in flounder erythrocytes (38), skate renal tubules (23), mammalian brain cells (35, $37,39)$, and renal medullary cells (40-42) indicate that regulation of transmembrane flux of osmoprotective molecules is a critical component of cell volume regulation during exposure to anisotonic media. Oral administration of taurine analogues to rats before induction of hypernatremic dehydration supplements the cerebral pool of osmolytes and confers protection against cell shrinkage during hypernatremia (8). This suggests that brain cells can regulate the transport of osmoprotective molecules and modulate the cytosolic levels of vital osmolytes. The present studies confirm this speculation and indicate that hypernatremic dehydration of modest severity and duration provokes an adaptive increase in cerebral taurine transport. This is consistent with the observation that C6 glioma cells display enhanced uptake of myo-inositol, another nonperturbing, organic osmoprotective molecule, when they are cultured in hyperosmolal media (43). Increased transport of myo-inositol, betaine, and glycerophosphorylcholine has also been documented in renal medullary cells exposed to hyperosmolal media $(41,42,44)$, and basolateral taurine transport is enhanced in Madin-Darby canine kidney cells exposed to hyperosmolar (500 mosmol $/ \mathrm{kg}$ ) media (45).

A recent report has questioned whether taurine is an important 
cerebral osmolyte in adult rats subjected to salt loading (32). Heilig et al. (32) used nuclear magnetic resonance spectroscopy of brain homogenates and noted that although there was a significant rise in the cerebral content of amino acids during chronic hypernatremia the bulk of the increase involved glutamic acid and glutamine. The taurine peak height was low, and significant changes in the brain content of this amino acid could not be resolved with this experimental technique. These authors concluded that taurine is not a cerebral osmoprotective molecule in adult rats. However, taurine is an abundant amino acid in the adult brain of nearly all mammalian species, and the high brain levels of taurine observed by previous authors $(5,6)$ are at variance with the inconsequential cerebral taurine content measured by Heilig et al. (32). In addition, in both the rat and mouse, the absolute magnitude of the change in cerebral taurine content during hypernatremia ranked first or second among all amino acids $(46,47)$. We have demonstrated an adaptive increase in cerebral taurine uptake during streptozotocin-induced hyperglycemia of $7 \mathrm{~d}$ duration (48) and acute uremia (49), and a reduction in brain taurine uptake during hyponatremia lasting $48 \mathrm{~h}(50)$. Finally, a recent study indicated that, in rats, taurine is an important osmolyte during chronic ( $7 \mathrm{~d}$ ) hypernatremia of moderate or extreme severity. Thus, cerebral taurine content increased by $38-79 \%$ when measured by conventional biochemical assays, HPLC, or nuclear magnetic resonance spectroscopy (51).

In conclusion, the results of these experiments indicate that during $48 \mathrm{~h}$ of hypernatremic dehydration of modest severity and duration there is a selective increase in the cerebral uptake of taurine, an osmoprotective amino acid. The adaptation in taurine uptake involves an increase in the $\mathrm{V}_{\max }$ of the highaffinity transporter without a concomitant alteration in the $\mathrm{Km}$. Based upon the strict ionic requirement for external $\mathrm{Na}^{+}$and $\mathrm{Cl}^{-}$for maximal synaptosomal taurine flux and the inhibition achieved by competing $\beta$-amino acids, the modulation of taurine transport during hyperosmolal states is likely to involve the $\beta$ amino acid carrier system. The inhibition of taurine uptake under hypernatremic conditions achieved by the addition of SITS and DIDS indicates that an intact anionic binding site is required to maximize this adaptive response.

Acknowledgments. The authors thank L. Finberg, M.D., who initially indicated the importance of this area of research, for guidance. P. Sarnaki and A. I. Arieff, M.D., assisted in establishing the method for the isolation of synaptosomes in our laboratory. Adrian Spitzer, M.D., made helpful comments and editorial suggestions in a review of the manuscript. Steven Moran prepared the electron micrographs of the synaptosomes. The authors thank Barbara Ho for her excellent secretarial assistance in the preparation of the manuscript.

\section{REFERENCES}

1. Pollack AS, Arieff AI 1980 Abnormalities of cell volume regulation and their functional consequences. Am J Physiol 239:F195-F205

2. Finberg L, Luttrell C, Redd H 1959 Pathogenesis of lesions in the nervous system in hypernatremic states. II. Experimental studies of gross anatomic changes and alterations of chemical composition of the tissues. Pediatrics 23:46-53

3. Somero GN 1986 Protons, osmolytes, and fitness of internal milieu for protein function. Am J Physiol 251:R197-R213

4. Star RA 1990 Hyperosmolar states. Am J Med Sci 300:402-412

5. Chesney RW 1985 Taurine: its biological role and clinical implications. Adv Pediatr 32:1-42

6. Jacobsen JG, Smith Jr LH 1968 Biochemistry and physiology of taurine and taurine derivatives. Physiol Rev 48:424-511

7. Finberg L, Kravath RE, Fleischman AR 1982 Water and Electrolytes in Pediatrics: Physiology, Pathophysiology and Treatment. WB Saunders Co, Philadelphia, pp 78-89

8. Trachtman H, del Pizzo R, Sturman JA, Huxtable RJ, Finberg L 1988 Taurine and osmoregulation. II. Administration of taurine analogues affords cerebral osmoprotection during chronic hypernatremic dehydration. Am J Dis Child 142:1194-1198

9. Kleeman CR 1989 Metabolic coma. Kidney Int 36:1 142-1158
10. Whittaker VP 1967 The morphology of fractions of rat forebrain synaptosomes separated on continuous sucrose density gradients. Biochem J 106:412-417

11. Trachtman H, Barbour R, Sturman JA, Finberg L 1988 Taurine and osmoregulation: taurine is a cerebral osmoprotective molecule in chronic hypernatremic dehydration. Pediatr Res 23:35-39

12. Fraser CL, Sarnacki P, Arieff AI 1985 Abnormal sodium transport in synaptosomes from brain of uremic rats. J Clin Invest 75:2014-2023

13. Omura T, Takesue S 1970 A new method for simultaneous purification of cytochrome b5 and NADPH-cytochrome $\mathrm{c}$ reductase from rat liver microsomes. J Biochem 67:249-257

14. Kontro P, Oja SS 1978 Taurine uptake by rat brain synaptosomes. J Neurochem 30:1297-1304

15. Kontro P, Oja SS 1978 Sodium dependence of taurine uptake in rat brain synaptosomes. Neuroscience 3:761-765

16. Snedecor GW, Cochran WG 1980 Statistical Methods, 7th Ed. The Iowa University Press, Ames, IA

17. Dantzler WH, Silbernagl S 1976 Renal tubular reabsorption of taurine, gammaaminobutyric acid (GABA) and $\beta$-alanine studies by continuous microperfusion. Pflugers Arch 367:123-135

18. Satoh O, Koyama SY, Yamada K, Kawasaki T 1991 Changes in amino acid and glucose transport in brush border membrane vesicles of hyperglycemic guinea-pig small intestine. Biochim Biophys Acta 1063:155-161

19. Banks MA, Martin WG, Pailes WH, Castranova V 1989 Taurine uptake by isolated alveolar macrophages and type II cells. J Appl Physiol 66:10791086

20. Chesney RW, Gusowski N, Dabbagh S, Thiessen M, Padilla M, Diehl A 1985 Factors affecting the transport of $\beta$-amino acids in the rat renal brush border membrane vesicles. The role of chloride. Biochem Biophys Acta 812:702712

21. Chesney RW, Gusowski S, Dabbagh S 1985 Renal cortex taurine content regulates renal adaptive response to altered dietary intake of sulfur amino acids. J Clin Invest 76:2213-2221

22. Zelikovic I, Stejskal-Lorenz E, Lohstroh P, Budreau A, Chesney RW 1989 Anion dependence of taurine transport by rat renal brush-border membrane vesicles. Am J Physiol 256:F646-F655

23. King PA, Beyenbach KW, Goldstein L 1982 Taurine transport by isolated flounder renal tubules. J Exp Zool 223:103-114

24. Wolff NA, Perlman DF, Goldstein L 1986 Ionic requirements of peritubular taurine transport in Fundulus kidney. Am J Physiol 250:R984-R990

25. Kimelberg HK, Goderie SK, Higman S, Pang S, Waniewski RA 1990 Swellinginduced release of glutamate, aspartate and taurine from astrocyte cultures. J Neurosci 10:1583-1591

26. Goldstein L, Brill SR, Freund EV 1990 Activation of taurine efflux in hypotonically stressed elasmobranch cells: inhibition by stilbene disulfonates. $J$ Exp Zool 254:114-118

27. Miyamoto Y, Balkovetz DF, Leibach FH, Mahesh VB, Ganapathy V 1988 $\mathrm{Na}^{+}+\mathrm{Cl}^{-}$-gradient-driven, high affinity, uphill transport of taurine in human placental brush-border membrane vesicles. FEBS Lett 231:263-267

28. Tayarani I, Cloez I, Lefauconnier JM, Bourre JM 1989 Sodium-dependent high-affinity uptake of taurine by isolated rat brain capillaries. Biochim Biophys Acta 985:168-172

29. Meiners BA, Speth RC, Bresolin N, Huxtable RJ, Yamamura HI 1980 Sodiumdependent, high affinity taurine transport into rat brain synaptosomes. Fed Proc 39:2695-2700

30. Chesney RW, Gusowski N, Zelikovic I 1986 Membrane fluidity and phospholipid composition in relation to sulfur amino acid intake in brush border membranes of rat kidney. Pediatr Res 20:1305-1309

31. Huxtable RJ, Crosswell S, Parker D 1989 Phospholipid composition and taurine content of synaptosomes in developing rat brain. Neurochem Int $15: 233-238$

32. Heilig CW, Stromski ME, Blumenfeld JD, Lee JP, Gullans SR 1989 Characterization of the major brain osmolytes that accumulate in salt-loaded rats. Am J Physiol 257:F1108-F1116

33. Blumenfeld JD, Hebert SC, Heilig CW, Balschi JA, Stromski ME, Gullans SR 1989 Organic osmolytes in inner medulla of Brattleboro rat: effects of ADH and dehydration. Am $\mathbf{J}$ Physiol 256:F916-F922

34. Gullans SR, Blumenfeld JD, Balschi JA, Kaleta M, Brenner RM, Heilig CW, Hebert SC 1988 Accumulation of major osmolytes in rat renal inner medulla in dehydration. Am J Physiol 255:F626-F634

35. Pesantes-Morales H, Schousboe A 1988 Volume regulation in astrocytes: a role for taurine as an osmoeffector. J Neurosci Res 20:505-509

36. Pierce SK 1982 Invertebrate cell volume control mechanisms: a coordinated use of intracellular amino acids and inorganic ions as osmotic solute. Biol Bull 163:405-419

37. Solis JM, Herranz AS, Herreras O, Lerma J, del Rio RM 1988 Does taurine act as an osmoregulatory substance in the rat brain? Neurosci Lett 91:53-58

38. Fugelli K, Thoroed SM 1986 Taurine transport associated with cell volume regulation in flounder erythrocytes under anisosmotic conditions. J Physiol $374: 245-261$

39. Walz W, Allen AF 1987 Evaluation of the osmoregulatory function of taurine in brain cells. Exp Brain Res 68:290-298

40. Bagnasco SM, Murphy HR, Bedford JJ, Burg MB 1988 Osmoregulation by 
slow changes in aldose reductase and rapid changes in sorbitol flux. Am J Physiol 254:C788-C792

41. Nakanishi T, Turner RJ, Burg MB 1989 Osmoregulatory changes in myoinositol transport by renal cells. Proc Natl Acad Sci USA 86:6002-6006

42. Nakanishi T, Burg MB 1989 Osmoregulation of glycerophosphorylcholine content of mammalian renal cells. Am J Physiol 257:C795-C801

43. Strange K, Morrison R, Heilig CW, DePietro S, Gullans SR 1991 Upregulation of inositol transport mediates inositol accumulation in hyperosmolar brain cells. Am J Physiol 260:C784-C790

44. Nakanishi T, Burg MB 1989 Osmoregulatory fluxes of myo-inositol and betaine in renal cells. Am J Physiol 257:C964-C970

45. Uchida S, Nakanishi T, Kwon HM, Preston AS, Handler JS 1991 Taurine behaves as an osmolyte in Madin-Darby canine kidney cells: protection by polarized, regulated transport of taurine. J Clin Invest 88:656-662
46. Chan PH, Fishman RA 1979 Elevation of rat brain amino acids, ammonia and idiogenic osmoles induced by hyperosmolality. Brain Res 161:293-301

47. Thurston JH, Hauhart RE, Dirgo JA 1980 Taurine: a role in osmotic regulation of mammalian brain and possible clinical significance. Life Sci 26:15611568

48. Trachtman H, Futterweit S, Sturman JA 1992 Cerebral taurine transport is increased during streptozocin-induced diabetes in rats. Diabetes (in press)

49. Trachtman H, Rizzo J, Futterweit S 1990 Taurine transport is increased in synaptosomes isolated from the brain of rats with acute renal failure. J Am Soc Nephrol 1:605(abstr)

50. Trachtman H, Futterweit S 1989 Taurine transport is decreased in synaptosomes isolated from the brain of rats with acute hyponatremia. Clin Res 37:868A(abstr)

51. Lien YHH, Shapiro JI, Chan L 1990 Effects of hypernatremia on organic brain osmoles. J Clin Invest 85:1427-1435 